\section{Journal of the Institute of Wood Science}

IN 1957 the Institute of Wood Science was inaugurated for the advancement of timber research and technology, and the first number of the Society's journal has now been published (Journal of the Institute of Wood Science, No. 1, March 1958. Pp. $\mathrm{i} \succ$ 64. 15s.). Its scope is to include original papers, both in research and in technology, and reports of lectures and discussions at the Society's meetings. Research on timber is a very wide subject and involves many scientific disciplines, biological, physical, chemical and engineering, and the new journal should have a varied and interesting range of papers to publish. This is reflected in the first number, the contents of which includes such diverse subjects as variations in structure occurring during growth, the physiology of cambial activity, ultrasonic-pulse technique in investigations of strength, and the acidity of wood. All, as would be expected, have practical application in view, so that the journal should have appeal both for scientific and technological workers alike.

\section{A New Estonian Natural History Journal}

THE Academy of Sciences of the Estonian Soviet Socialist Republic has produced a new journal of science, Eesti Loodus (Estonian Nature). Published bi-monthly, the articles are written in Estonian; but each issue contains abstracts in the English language which have been prepared by a translator with a remarkable flair for the right word and phrase. The articles cover a wide range of subjects including such topies as the artificial earth satellite; cliffs of the Jaagarahu Strata; Virginia witch-hazel in the Estonian S.S.R.; insects on snow; the practical application of the infra-red quenching of luminescence; the dependence of the external form of tetracorals on environmental conditions; the distribution of steppe plants and phytogeographical boundaries in Estonia ; the 'Snowman'; ball lightning; the Elva Sandr, its formation and early hydrography ; plant parasitic nematodes in Estonia and the protection of inanimate nature in the Estonian S.S.R. Each number also contains a section giving details of outstanding scientific discoveries as well as popular sections for young people and general readers. The editorial office is 5 Hariduse Street, Tartu, Estonian S.S.R.

\section{The Geological Museum}

TrE Geological Museum at South Kensington has just issued an attractive short guide to the exhibits (pp. ii +32. London: H.M. Stationery Office, 1958. 1s. 6d.). The publication is intended primarily for the visitor who wishes to make a short tour of the Museum and obtain a general idea of the scope of the display collections. At the outset is given a short history of the Museum and a sketeh plan of the general arrangement. The three floors are then described in more detail again, with plans of particular sections. The general arrangement of the guide thus conforms with previous editions. The format is good and pleasing, though it is unfortunate that the method of reproduction of the photographic illustrations scarcely does justice to the originals.

\section{The Wild-Fowl Trust}

BESIDES a wealth of characteristic sketches by the Director, the ninth annual report of the Wild-Fowl Trust contains a remarkable collection of photographs of wild-fowl taken by some of the world's best natural history photographers (edited by Peter Scott and Hugh Boyd. London: Country Life limited, 1958. 10s. net). Then there is a series of articles by members of the staff and friends of the Trust which not only records developments and researches at Slimbridge but also describes wildfowl collections and investigations in many other parts of the world. Probably the biggest event in the life of the Trust during 1956-57 was the opening of the Peakirk Waterfowl Gardens by H.R.H. the Duke of Gloucester on April 12, 1957. One of the main objects of this scheme is to provide sufficient funds to enable the Trust to take on the lease and maintenance of Borough Fen Decoy, which has been operated by members of the Williams family since its construction in about 1640. It is also of great value to have a place which can be used as a reservoir for birds, and an alternative collection, as the danger of epidemics among the birds at Slimbridge cannot be entirely dismissed.

During the period popular interest in the collection at Slimbridge continued to grow in a gratifying way. The total number of visitors in the calendar year 1956 was about 120,000. In 1957 this figure was reached before the end of August. Membership stood at 5,094 in January 1957-another record figure. The collections at Slimbridge and Peakirk now contain about 1,747 birds of 148 forms (116 species). In 1957,770 young birds, of 72 forms, were reared in the collection. Extensive studies have begun in two fields new to the Trust's research programme: a systematic investigation into the food of wild fowl and the use of aircraft in surveys of the distribution and number of wildfowl.

\section{Demonstration Meeting on Biological Acoustics}

During the fifteenth International Congress of Zoology, held in London during July 16-23, the Committee for Biological Acoustics organized a demonstration meeting to illustrate the wide range of research in this comparatively new and expanding field. The meeting, held on July 21 in the Imperial College of Science and Technology, London, was open to all members of the Congress and attracted more than one hundred visitors. Work on the reception of human speech was shown by Dr. E. C. Cherry and colleagues of the Department of Electrical Engineering, Imperial College, and demonstrated how recognition of electronically 'clipped' speech is accomplished. Binaural location of sounds was also shown. The progress made in the United States in under. water recording was emphasized by a demonstration of the acoustic emission of whales by Dr. W. E. Schevill, of the Oceanographic Institution, Woods Hole, Massachusetts. The technical problems inherent in such studies were made apparent by recordings of American marine noises made by Dr. Martin Johnson, of the Scripps Institution of Oceanography, University of California; a high-level background noise interfering with recording of fish noises was eventually traced by him to its origin in large populations of 'snapping shrimps'. The single, irregular cracking noise produced by each individual shrimp drifting in the sea, when multiplied by the number of shrimps within range of the microphone, produces a frizzing background noise of high level. British interest in underwater acoustics was underlined by Mr. N. B. Marshall, of the Department of Zoology, British Museum (Natural History), who said that it was hoped that a start would soon be made on recording in the English Channel. 